\title{
Excitotoxic Injury to Retinal Ganglion Cells
}

\author{
William A. Hare, Cun-Jian Dong and Larry Wheeler \\ Allergan, Inc. \\ USA
}

\section{Introduction}

In the retina, as in other parts of the central nervous system, excitatory synaptic transmission is mediated by glutamate. Excitatory synaptic transmission begins typically with a depolarization of the presynaptic (axon) terminal membrane resulting in an influx of calcium ions from the extracellular space into the presynaptic terminal. This influx of calcium ions triggers release of glutamate from the presynaptic terminal into the synaptic cleft. Glutamate then diffuses across the synaptic cleft and binds to ion channels of the postsynaptic membrane (neuronal dendrite). These glutamate-gated channels allow sodium and calcium ions to flow from the extracellular space into the post-synaptic dendritic compartment, thereby depolarizing or "exciting" the post-synaptic neuronal membrane. In order to preserve both the temporal properties and local specificity of synaptic transmission, glutamate must be cleared rapidly from the extracellular space by transporters located in neurons as well as glial cells.

It has been shown that excessive levels of excitatory activity can result in excitotoxic neuronal injury that is mediated ultimately by elevation of intracellular sodium and calcium concentration. Excitotoxic neuronal injury can be triggered by a wide range of primary insults and associated mechanisms that vary with location within the neuronal membrane compartment. In retinal ganglion cells (RGCs), somato-dendritic membrane is specialized for receiving synaptic inputs and integrating those conductance changes while axonal membrane is specialized for transmission of action potentials and synaptic communication. RGC dendritic membrane thus has a high density of glutamate-gated channels (Aizenman et al., 1988; Massey \& Miller, 1990; Diamond \& Copenhagen, 1993) while the axonal membrane has a high density of voltage-gated sodium channels (Pellegrino \& Ritchie, 1984; Craner et al., 2003). RGC axons are not known to express glutamatergic channels but voltage-gated sodium channels are also expressed in somato-dendritic membrane (Wollner et al., 1988; Kaneda \& Kaneko, 1991). Excessive activation of either glutamate-gated channels or voltagegated sodium channels can result in excitotoxic injury to RGCs. Although other membrane conductances may, under some circumstances, drive excitotoxic RGC injury, this chapter will focus on mechanisms for RGC injury resulting from glutamate-gated channels and voltage-gated sodium channels.

\section{Glutamatergic excitotoxicity}

There are two general classes of glutamate-gated ion channel in the CNS: the NMDA-type and the non-NMDA type (Choi, 1988; Schoepfer et al., 1994). For both classes, glutamate is 
the normal endogenous ligand for channel activation but they may be distinguished by their selectivity for molecules that can bind to and activate the channel. NMDA-type channels are activated selectively by N-methyl-D-aspartate while non-NMDA channels are activated selectively by either kainate or a-amino-3-hydroxy-5-methyl-4-isoxazole-proprionic acid (AMPA). Both sub-types are permeable to sodium and calcium ions and neurons may be injured by excessive activity of either subtype. However, due to the relatively high calcium permeability of NMDA-type channels, neurons are particularly sensitive to injury resulting from overactivity of this channel subtype (Rothman \& Olney, 1987). RGCs are known to express NMDA-type channels and glutamatergic excitotoxicity, mediated by NMDA channels, has been shown to be an important mechanism for RGC injury in a wide range of animal models for both acute and chronic disease including retinal ischemia (Lam et al., 1997; Lagreze et al., 1998), and glaucoma (Gu et al., 2000; WoldeMussie et al., 2002; Schuettauf et al., 2002; Hare et al., 2004a, 2004b).

Some key features of NMDA channel function are summarized in Figure 1. Under "resting" conditions, the trans-membrane potential is highly negative and the channel conductance gate is closed (A). At this high negative "resting" membrane potential, a magnesium ion is bound to a site within the channel conductance pore. When glutamate (or NMDA) binds to its receptor site, the channel opens but cannot conduct sodium or calcium ions due to block of the channel pore by magnesium (B). Unbinding of magnesium from its site within the pore requires depolarization of the neuronal membrane. That is, the probability of magnesium binding decreases with decreasing membrane polarization (C). The NMDA channel thus acts as a coincidence detector or, in the parlance of digital logic, an "AND" gate. In other words, the NMDA channel requires the simultaneous activity of non-NMDA channel synaptic input (or some other depolarizing event) in order to be "active", regardless of whether or not the channel has been "opened" by glutamate binding.

Any insult or condition that leads either to an increase in extracellular levels of glutamate or to an increase in the effect of glutamate at the post-synaptic membrane may trigger excitiotoxic neuronal injury. Ischemic insult provides one example for excitotoxic neuronal injury. Under conditions of metabolic insufficiency, cellular energy failure will be associated with loss of function in energy-dependent membrane transporters. Failure of the sodium/potassium exchanger results in loss of the transmembrane sodium gradient and depolarization of the "resting" membrane potential. Membrane dopolarization, in turn, increases the release of glutamate from presynaptic terminals and also decreases the voltage-dependent magnesium block of NMDA channel pores in the post-synaptic membrane. The resulting increase in glutamate-gated influx of sodium and calcium ions further depolarizes the cell membrane and also leads directly to cell injury through activation of calcium-dependent mechanisms as well as loss of function in membrane transporters that rely on the trans-membrane sodium gradient.

\subsection{Glutamatergic excitotoxicity in RGCs}

Glutamatergic neuronal excitotoxicity, originally described in the retina (Lucas \& Newhouse, 1957), results from excessive activity of glutamate-gated ion channels and consequent increase in the intracellular levels of both sodium and calcium ions. RGCs are known to express both NMDA and non-NMDA type glutamataergic channels and are sensitive to injury from exposure to exogenously applied NMDA (Siliprandi et al., 1992; 
Pellegrini \& Lipton, 1993; Pang et al., 1999; Luo et al., 2001). In addition, systemic treatment with selective NMDA antagonists has shown that NMDA-type glutamatergic membrane channels make a significant contribution to RGC injury in rat (Gu et al., 2000; WoldeMussie et al., 2002) and monkey (Hare et al., 2004a, 2004b) models of experimental glaucoma.

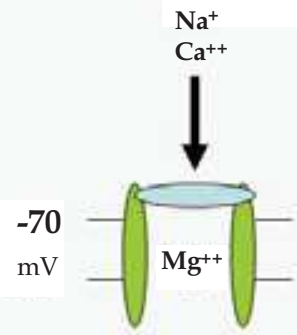

A

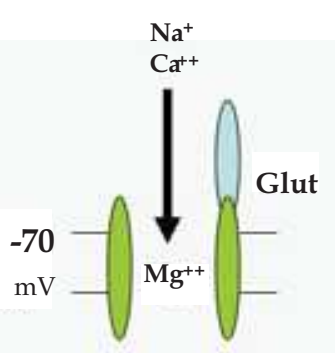

B

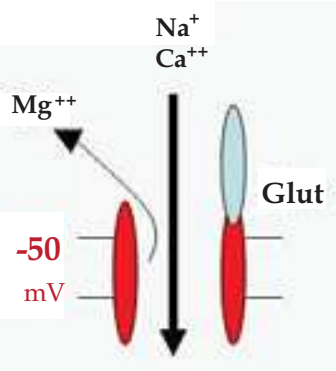

C

NMDA Channel
A. Channel closed + magnesium block
B. Channel open + magnesium block
C. Channel open + no magnesium block
D. Channel open + memantine block

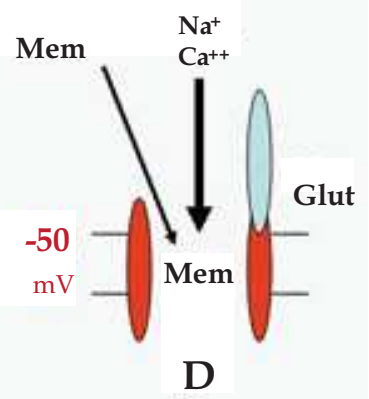

Fig. 1. Function of the NMDA-type glutamate-gated channel. Channel opening (B) requires binding of both glutamate (Glut) and glycine (not shown). See also (Choi, 1988)

Acute glutamatergic excitotoxic responses can be observed in electrophysiological recordings from single RGCs in a dark-adapted, perfused, ex-vivo rabbit retina preparation as illustrated in Figure 2. For these experiments, simultaneous recordings of the electroretinogram (ERG) and single-unit RGC responses were made. The retinal sample, beginning at the inferior margin of the optic disk as shown in panel A, was mounted RGC (vitreal) side up in the perfusion chamber as shown in panel B. The transretinal potential (ERG) was recorded as the voltage between the bath electrode and the sub-retinal electrode. The spiking activity of a single RGC was recorded using a tungsten microelectrode and the bath electrode as reference. Dim stimuli (delay $=400 \mathrm{msec}$, duration $=10 \mathrm{msec}$ ) were generated using a bluegreen LED $(\lambda$ peak $=504 \mathrm{nM}$ ). RGCs were classified as either "ON" or "OFF" subtype based on the response to a dim stimulus of one second duration. ON RGCs respond to this stimulus with a burst of action potentials at the stimulus onset while OFF RGCs are inhibited by the stimulus and respond with a burst of action potentials at stimulus offset (not shown). 
A.

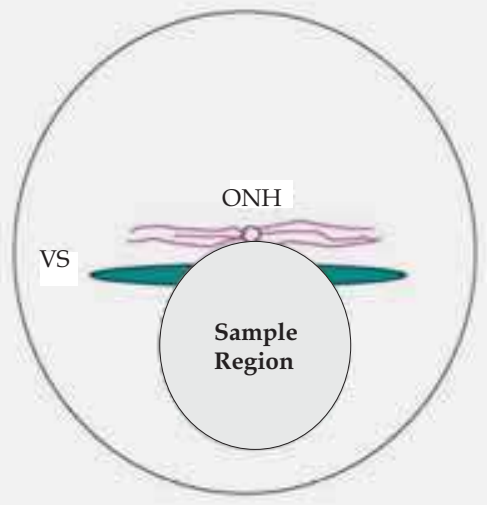

B.

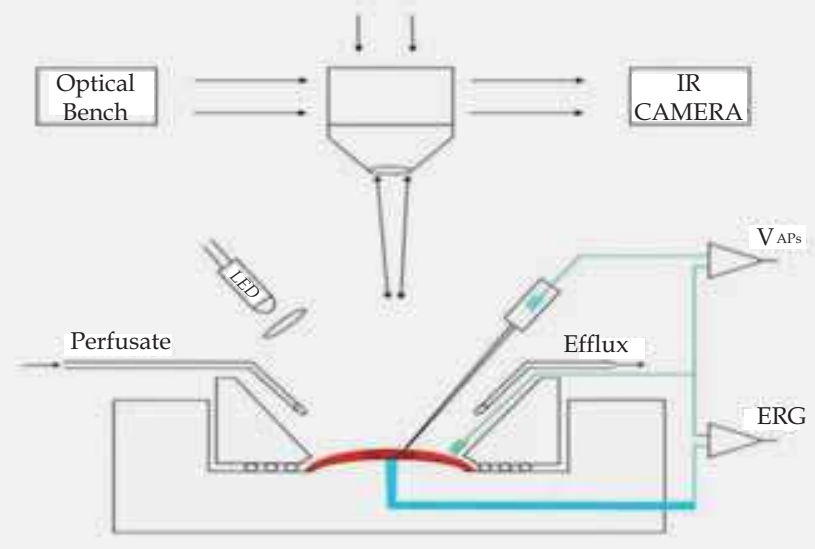

Fig. 2. Ex-vivo dark-adapted perfused rabbit retina preparation for simultaneous recording of the ERG and single-unit RGC activity. RGCs were classified as either "ON" or "OFF" subtype

Figure 3A shows the ERG (top trace) and single-unit RGC (bottom trace) responses to a dim flash delivered at $400 \mathrm{msec}$ (vertical line). Note that the dim flash is below the ERG a-wave threshold and elicits a purely b-wave response. This OFF RGC exhibits a tonic level of spiking activity and responds to the dim flash with a burst of spikes at a latency of approximately $100 \mathrm{msec}$. At 2 minutes following continuous bath application of $200 \mu \mathrm{M}$ NMDA (panel B), there is an obvious increase in the tonic level of RGC spiking activity, a reduction in spike amplitude, and no significant effect on the ERG. After 6 minutes of NMDA exposure (panel C), the RGC spike generation mechanism has failed. At 2 minutes following the switch to perfusion with $200 \mu \mathrm{M}$ NMDA in combination with $10 \mu \mathrm{M}$ memantine (a selective NMDA channel blocker), the RGC spike generation mechanism has 
begun to recover. The RGC has recovered to CONTROL levels of tonic spike frequency and amplitude by 4 minutes following addition of memantine. Clearly, application of exogenous NMDA results in an increase in tonic RGC spiking activity with a consequent rundown of the trans-membrane sodium gradient and loss of spike generation. Addition of memantine is able to completely reverse the effects of continuously applied NMDA and restore normal levels of tonic spike activity including responses to light stimuli.
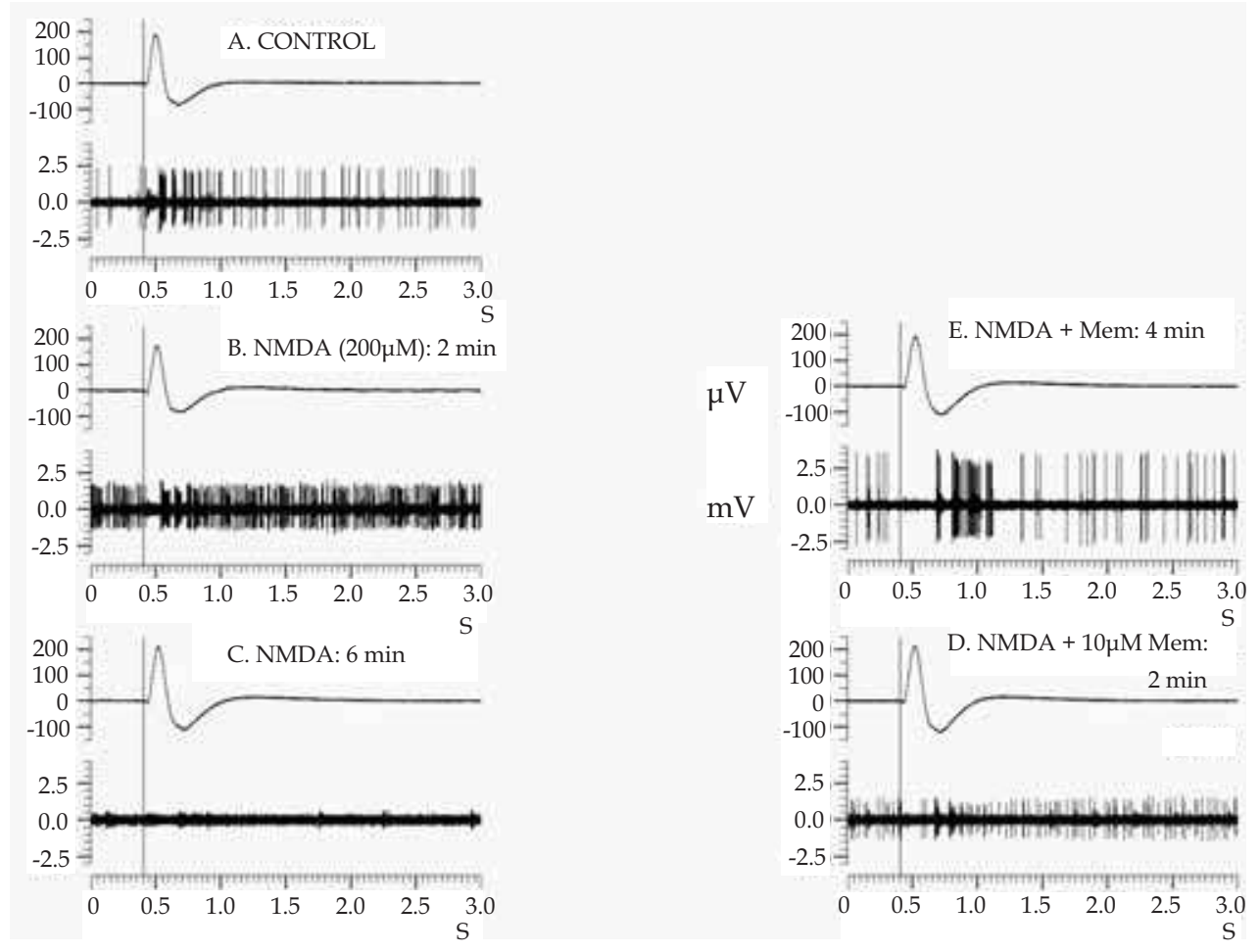

Fig. 3. Exogenous application of NMDA results in excitotoxicity in an OFF RGC that is reversed by co-application of memantine, an uncompetitive NMDA open-channel blocker. In all panels: top trace $=E R G$, bottom trace $=$ single-unit RGC spikes. $10 \mathrm{msec}$ duration stimulus flash onset at $400 \mathrm{msec}$ (vertical line). ERG $=$ microvolts. RGC $=$ millivolts. (From Hare \& Wheeler 2009)

Memantine is an "open channel blocker" of the NMDA channel pore (Pelligrini et al., 1992; Chen \& Lipton, 1997). In order for memantine to access its binding site within the pore, the channel must be in the open configuration following binding of glutamate (or NMDA) and magnesium must unbind from its site within the pore (see Figure 1). These properties of memantine binding make it more effective to block very high (pathological) levels of NMDA receptor activity while having a lesser effect on lower (normal) levels of activity. Figure 4 summarizes results which show that application of NMDA to a different OFF RGC has a similar effect to increase tonic RGC spiking frequency and to reduce spike amplitude. In this case, NMDA-induced excitotoxic RGC activity was reversed completely 
by co-application of $30 \mu \mathrm{M}$ AP5 (2-amino-5-phosphonovaleric acid). Unlike memantine, AP5 competes with glutamate (or NMDA) for its binding site on the NMDA receptor to block channel opening.
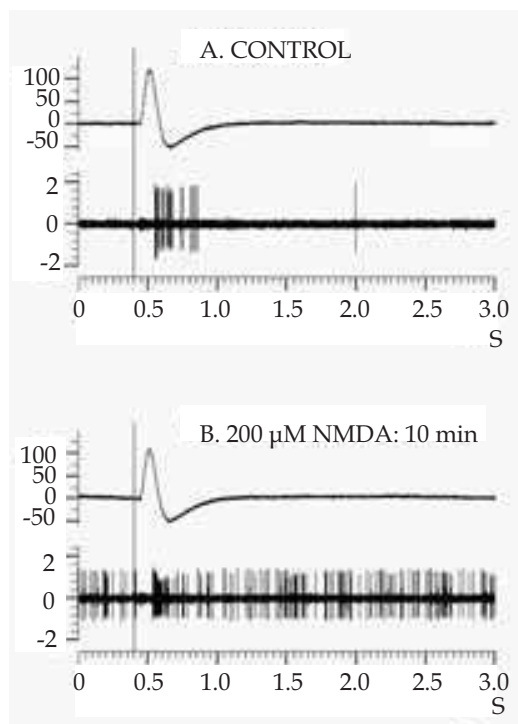
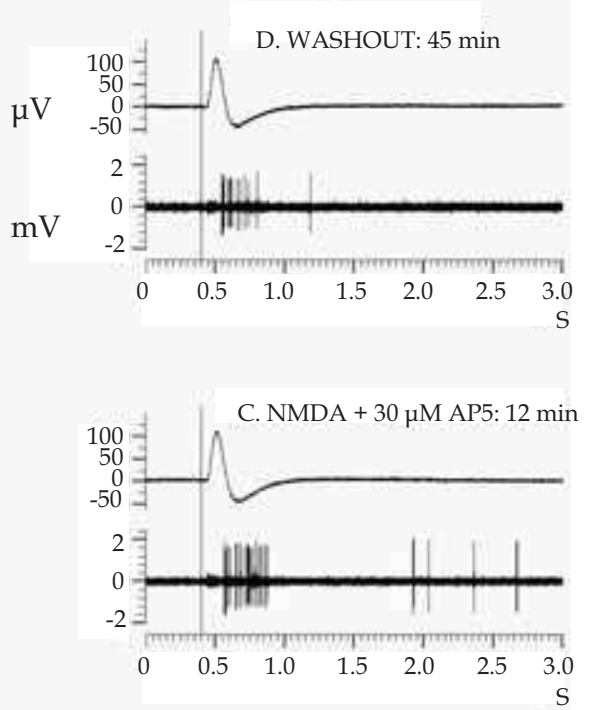

Fig. 4. NMDA-induced excitotoxicity in an OFF RGC is completely reversed by coapplication of AP5, a competitive NMDA receptor antagonist. (From Hare \& Wheeler, 2009)

Exogenous application of NMDA mimics the pathological condition where excessive release of glutamate into the extracellular space results in excitotoxic activity of NMDA receptors. Increased release of glutamate into the extracellular space has been reported in various models for experimental insults to CNS tissue including retina (Louzada-Junior et al., 1992; Neal et al., 1994; Kowluru et al., 2001; Nucci et al., 2005). RGCs are much less sensitive to exogenously applied glutamate since CNS tissue expresses high levels of glutamate transporters that, under normal conditions, provide for very tight regulation of extracellular glutamate levels. These transporters work to prevent exogenously applied glutamate from reaching increased levels at the post-synaptic membrane receptors. RGCs are much more sensitive to exogenously applied NMDA since it is not transported by these intrinsic glutamate buffer mechanisms. Under pathological conditions, failure of these glutamate transporters would be expected to contribute to elevations in extracellular glutamate that could drive excitotoxic RGC injury. For this reason, a different series of experiments used exogenous application of TBOA (DL-threo- $\beta$-benzyloxyaspartic acid) to block selectively retinal glutamate transporters (Izumi et al., 2002). Figure 5 shows that application of $50 \mu \mathrm{M}$ TBOA was associated with a rapid increase in tonic spiking of this OFF RGC and reduction of spike amplitude (panel B) followed by complete block of RGC spike generation (panel C). As was seen for reversal of NMDA-induced excitotoxicity, co-application of memantine produced a rapid recovery of both spike amplitude and tonic spike frequency toward control levels (panel D). Memantine washout in the presence of continuous application of TBOA was associated with the reappearance of excitotoxic RGC spiking activity (panel E). 

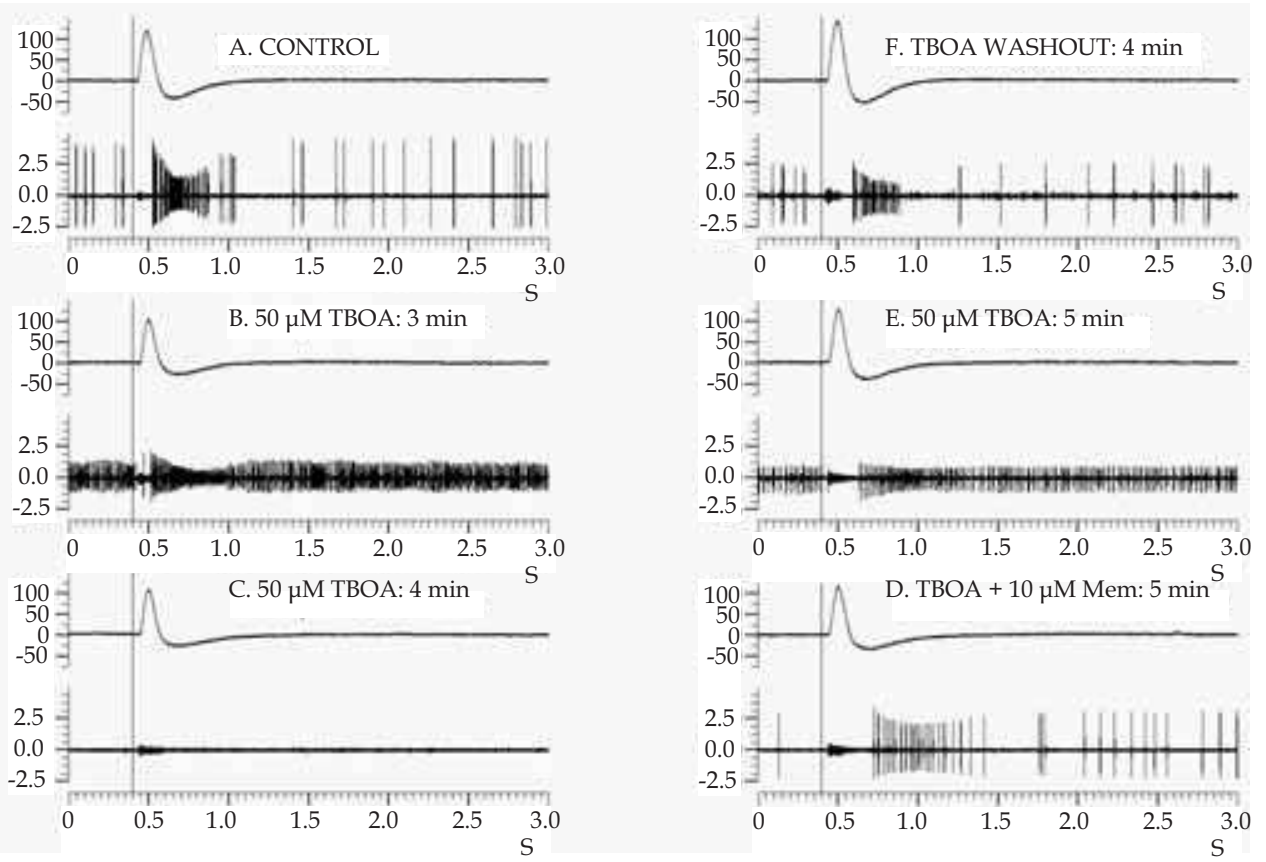

Fig. 5. For this OFF RGC, block of retinal glutamate transporters with TBOA results in excitotoxic activity that can be reversed by co-application of memantine. (From Hare \& Wheeler, 2009)

Membrane depolarization resulting from cellular energy failure or other causes is thought to play an important role in excitotoxic neuronal injury. Membrane depolarization is associated with decreased binding of magnesium at its blocking site within the NMDA channel pore (see Fig. 1). For this reason, when RGCs become chronically depolarized, excitotoxic levels of NMDA channel activity can occur even in the presence of otherwise "normal" levels of extrtacellular glutamate (Zeevalk \& Nicklas, 1992). The loss of voltagedependent magnesium block can be experimentally approximated by perfusion with magnesium-free solution. The results for the ON RGC summarized in Figure 6 show that the switch to zero magnesium solution was followed by an increased rate of spiking activity and reduction of spike amplitude (panel C). This excitotoxic response is similar to that seen following perfusion with either NMDA (see Fig. 3) or TBOA (see4 Fig. 5) and was also reversed by co-application of memantine (panel D). However, the decrease in spike amplitude (spike generation failure) seen in zero magnesium typically developed more slowly than spike generation loss resulting from either NMDA or TBOA.

\subsection{Regulation of NMDA receptor function in RGCs}

We have seen how the level of NMDA receptor activity in RGCs depends upon the amount of glutamate released from pre-synaptic neurons, the removal of glutamate from the extracellular space by glutamate transporters, and the degree of voltage-dependent magnesium block set by the RGC membrane potential. It has also been shown recently that activation of alpha- 2 adrenergic receptors reduces NMDA-induced responses in RGCs. This 

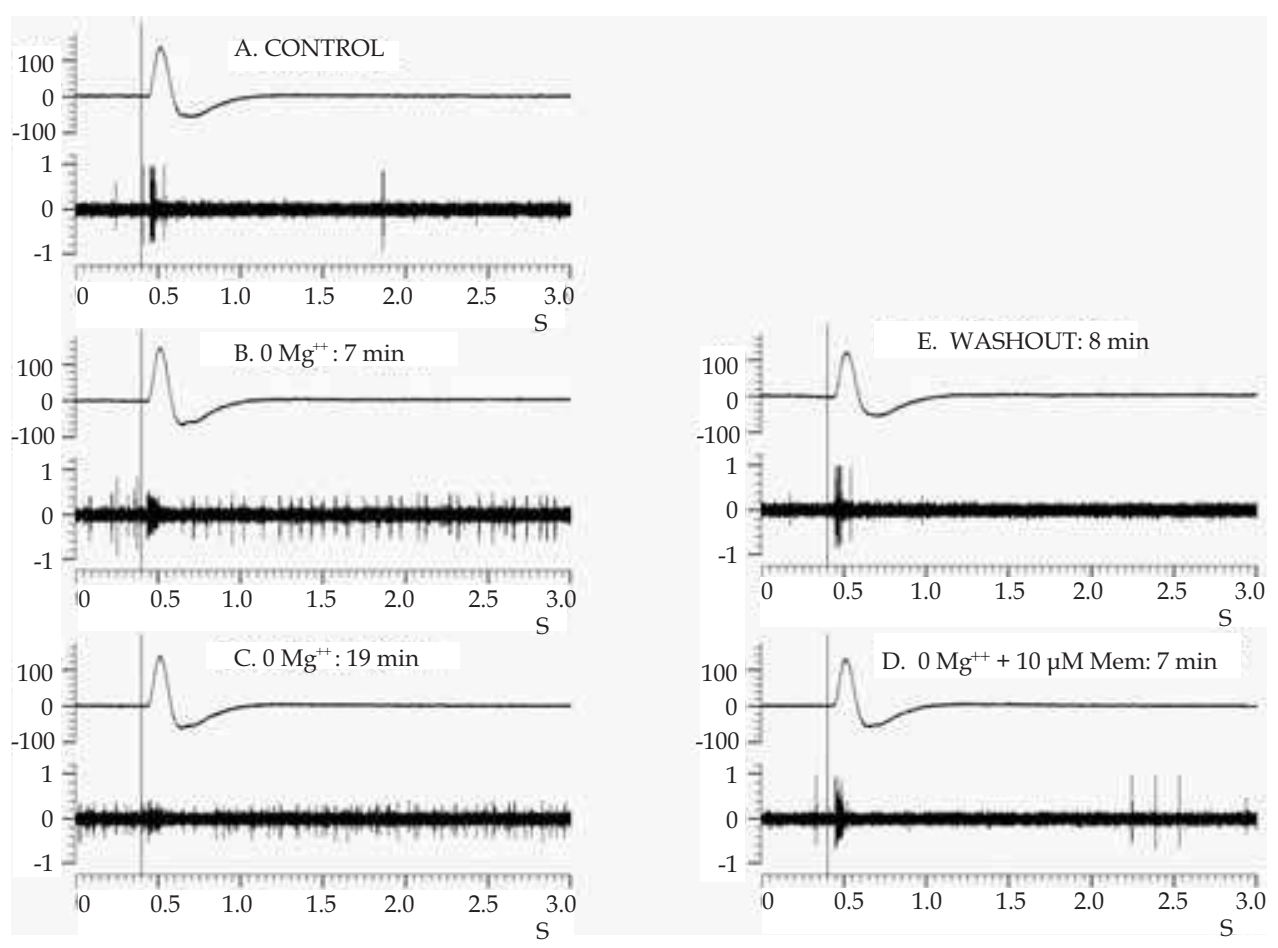

Fig. 6. Perfusion with zero magnesium results, for this ON RGC, in excitotocic activity that resembles that seen following application of either NMDA or TBOA and is also reversed by co-application of memantine. (From Hare \& Wheeler, 2009)

finding results from studies using simultaneous recordings of the membrane current and cytoplasmic calcium concentration changes induced by application of NMDA. For these experiments, whole-cell current recordings were made from RGCs in a flat-mounted, perfused, ex-vivo rat retina preparation as illustrated schematically in Figure 7. For these recordings, the RGC membrane is voltage-clamped at $-70 \mathrm{mV}$, close to the normal "resting" level. The recording pipette contained the calcium indicator Fluo-4 which was passively loaded into the RGC cytoplasm through diffusion. Activation of NMDA receptors was effected using local delivery of NMDA. RGC membrane current was measured using conventional voltage-clamp methods while cytoplasmic calcium measures were acquired with a spinning disk confocal fluorescence imaging system.

Results from one experiment are summarized in Figure 8 where the top panel traces represent recordings of RGC membrane current responses to local NMDA application (heavy black horizontal bar) and the bottom panel traces represent changes in cytoplasmic calcium concentration to the same NMDA applications. Note that under control conditions (red traces), NMDA induces an inward current representing an influx of sodium and calcium cations while this inward calcium flux produces an increase in cytoplasmic calcium. Continuous bath application of $10 \mu \mathrm{M}$ memantine is associated with a severe reduction in NMDA-induced membrane current and cytoplasmic calcium signal (green traces). This effect of memantine is rapidly reversed following washout (blue traces). 


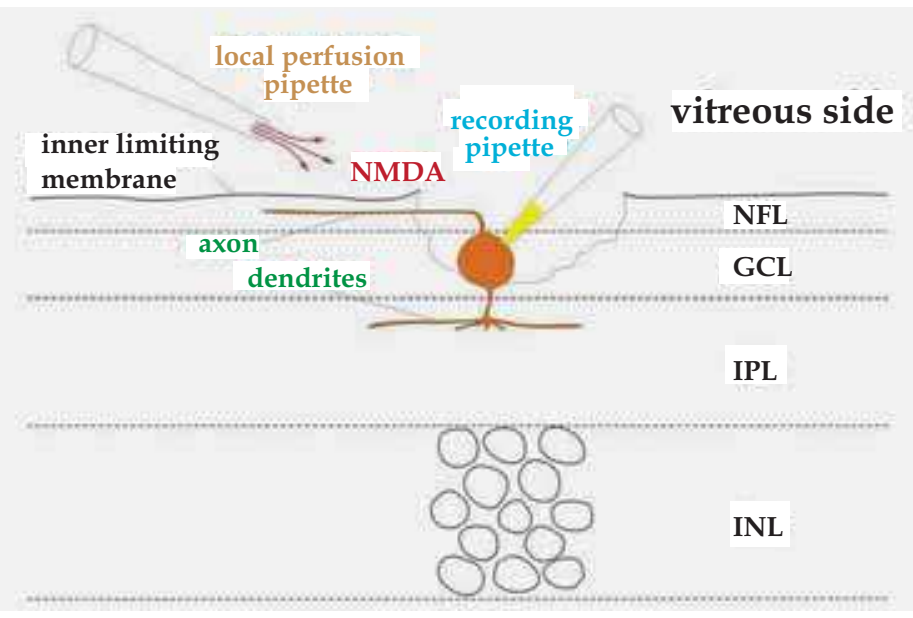

Fig. 7. Simultaneous measures of membrane current and cytoplasmic calcium level in a single RGC in the flat-mounted, perfused, ex-vivo rat retina. NFL (nerve fiber layer), GCL (ganglion cell layer), IPL (inner plexiform layer), INL (inner nuclear layer)

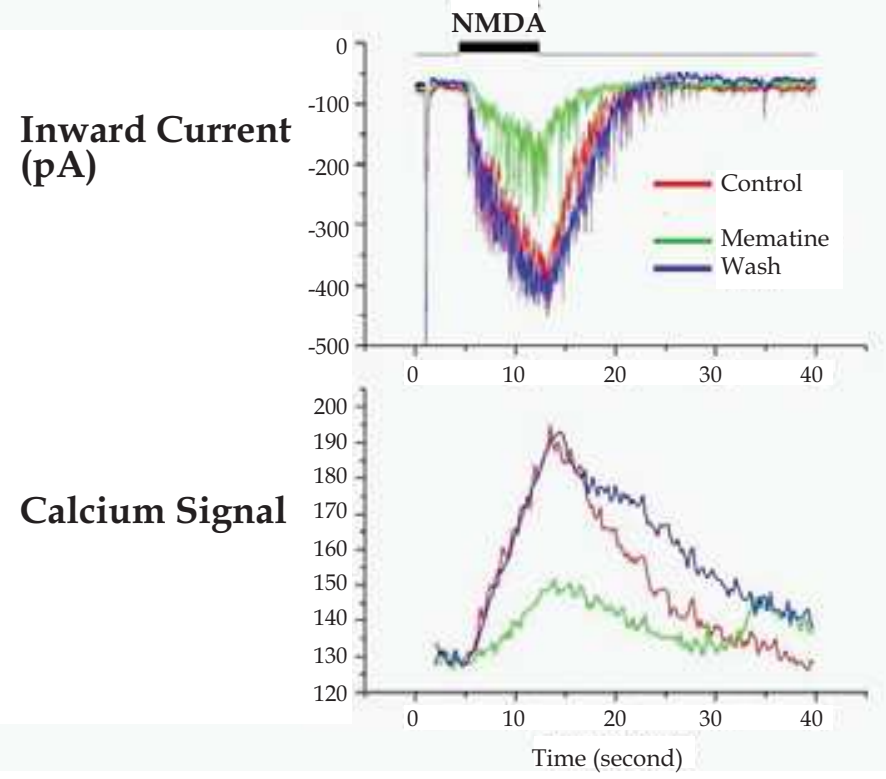

Fig. 8. NMDA-induced membrane current (upper panel) and cytoplasmic calcium signal (lower panel) in a single RGC are reduced by bath application of memantine

Recordings from a different RGC are summarized in Figure 9. The traces in panel A show that bath application of $3 \mu \mathrm{M}$ brimonidine, a selective alpha- 2 adrenergic receptor agonist, is associated with a reduction of both the NMDA-induced current and calcium signals by 
approximately $40 \%$ and $50 \%$, respectively. The summary results plotted in panel C show that this effect of brimonidine to reduce NMDA-induced current and calcium signals is blocked by co-application of $15 \mu \mathrm{M}$ atipamezole (a selective alpha-2 receptor antagonist) or by intracellular loading (via the patch pipette) of GDP $\beta S$, a G-protein inhibitor. These findings are consistent with the notion that alpha-2 receptor activation, through Gai mediated coupling, leads to inhibition of adenyl cylase and a consequent decline in cytoplasmic levels of cyclic AMP. In other experiments, intracellular application of SpcAMPS, a hydrolysis-resistant analog of cAMP, was also shown to block the effect of brimonidine to decrease NMDA-induced current and calcium signals (data not shown). Further confirmation that activation of alpha-2 receptors leads to a down regulation of NMDA receptor activity by reducing intracellular levels of cAMP is provided by results summarized in Figure 10. Intracellular application of either rolipram, a selective PDE4 inhibitor, or forskolin, an activator of adenyl cyclase, resulted in a block of the brimonidine effect.

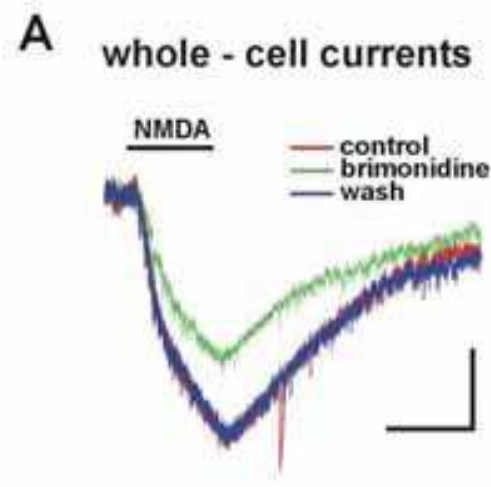

\section{cytosolic $\mathrm{Ca}^{++}$}

B
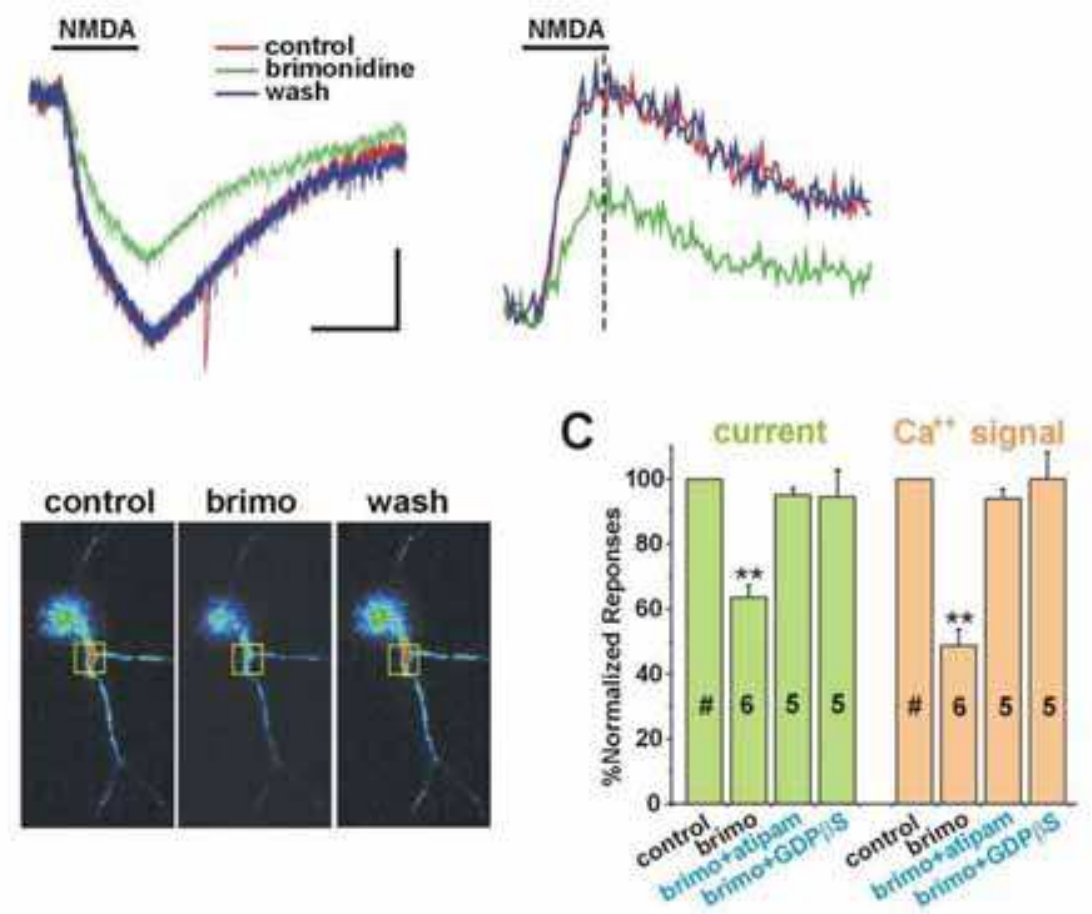

Fig. 9. Bath application of brimonidine reduces the magnitude of NMDA-induced current and calcium responses in RGCs. This effect is blocked by either an alpha- 2 receptor antagonist (atipamezole; bath application) or G protein inhibitor (GDP $\beta S$; intracellular application). The yellow windows in panel B indicate RGC region used for calcium measures. (From Dong et al., 2008) 
A
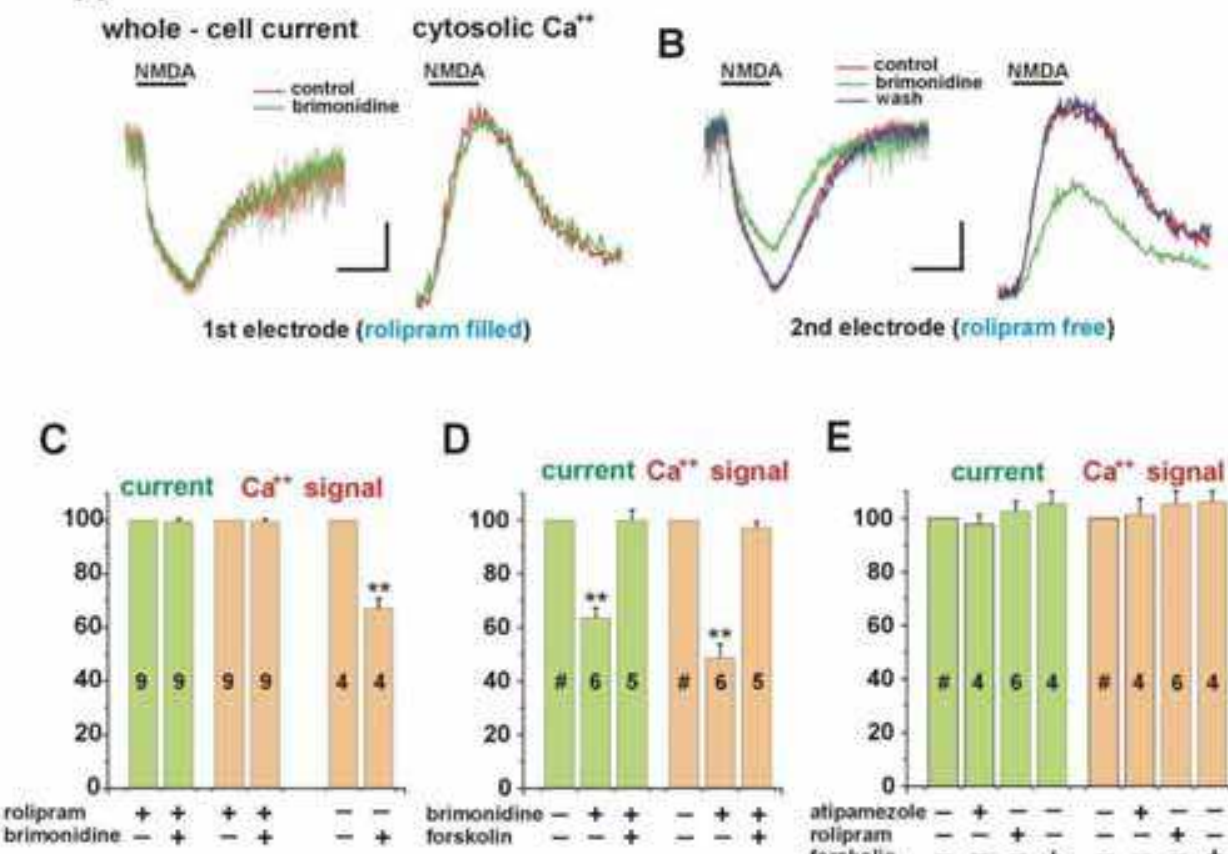

D

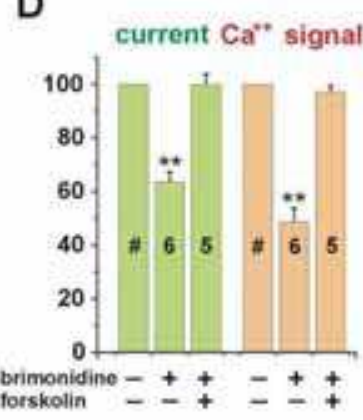

E

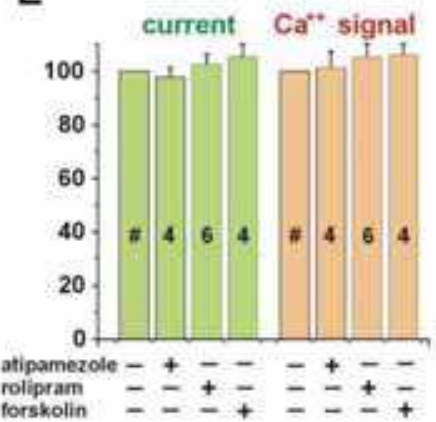

Fig. 10. Intracellular application of either rolipram (PDE4 inhibitor) or forskolin (adenyl cyclase activator) results in block of the brimonidine effect on NMDA-induced current or calcium responses in RGCs. (From Dong et al., 2008)

Results from recordings of NMDA-induced RGC responses in an ex-vivo rat retina thus show that NMDA channel function and, by extension, intracellular calcium concentration are regulated by apha-2 adrenergic receptors through Gai-coupled inhibition of adenyl cyclase. Brimonidine treatment has been shown to prevent damage in a wide range of animal models for RGC injury including experimental glaucoma (WoldeMussie et al., 2001; Kim et al., 2007), acute retinal ischemia (Donello et al., 2001; Lafuente et al., 2002; Lai et al., 2002), optic nerve mechanical injury (Yoles et al., 1999; Ma et al., 2009), and NMDA-induced retinal excitotoxicity (Metoki et al., 2005; Dong et al., 2008); all models in which NMDA receptors have been shown to play a significant role in driving RGC injury. Two of these, a rat model for experimental glaucoma and a rabbit model for intravitreal injection of NMDA, were used to demonstrate that the protective effects of brimonidine treatment result from alpha-2 receptor mediated inhibition of adenyl cyclase activity.

Figure 11 shows that, for the rat glaucoma model used in this study, laser photocoagulation of the perilimbal vessels and episceral veins was followed, on average, by an increase in intraocular pressure (IOP) from a control level of approximately $15 \mathrm{~mm} \mathrm{Hg}$ to approximately $30 \mathrm{~mm} \mathrm{Hg}$. RGC survival was quantified, at approximately 2 weeks following IOP elevation, by flat-mounting the retina and counting RGCs at 24 locations in the central and peripheral retina (panel A). RGCs were labeled using retrograde transport of rhrodamine-conjugated dextran delivered directly to the retrobulbar optic nerve (panel B). 
Untreated (control) glaucoma eyes lost, on average, approximately $30 \%$ of their RGCs (panel C). Continuous dosing, using subcutaneous osmotic pumps, with either memantine $(3 \mathrm{mg} / \mathrm{kg} /$ day) or brimonidine $(0.18 \mathrm{mg} / \mathrm{kg} /$ day) resulted in a reduction of RGC loss to less than $10 \%$. This protective effect of brimonidine was blocked by co-administration of either the selective PDE4 inhibitor, rolipram $(0.6 \mathrm{mg} / \mathrm{kg} /$ day $)$, or the selective alpha-2 receptor antagonist, atipamezole $(0.9 \mathrm{mg} / \mathrm{kg} /$ day $)$. None of these systemically delivered test agents had any significant effect on IOP in the laser treated eye (panel E).

A
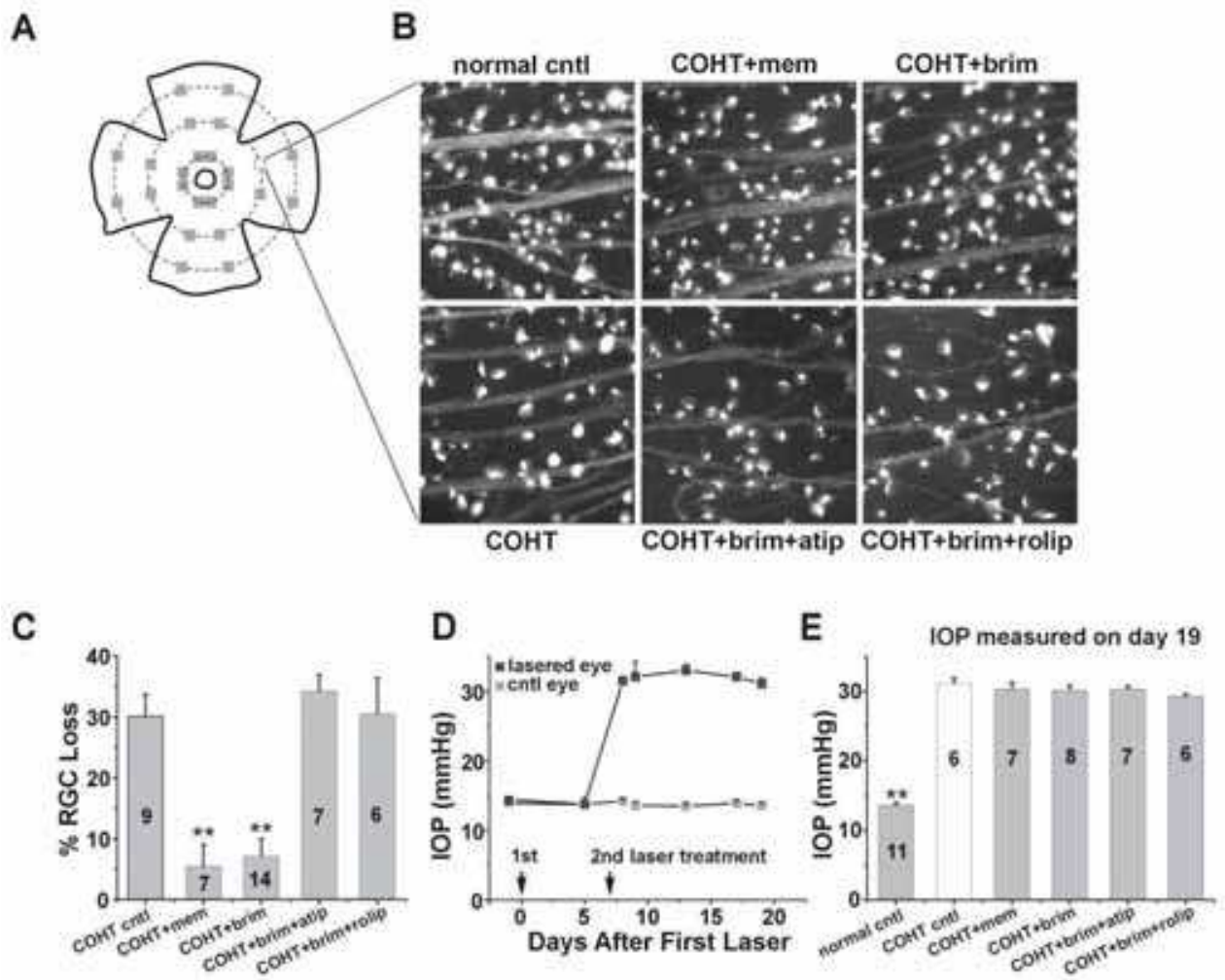

Fig. 11. Treatment with either memantine or brimonidine is associated with a reduction in the level of RGC loss in a rat model of experimental glaucoma. The protective effect of brimonidine treatment is blocked by co-administration of either an alpha-2 receptor antagonist (atipamezole) or an inhibitor of PDE4 (rolipram). (From Dong et al., 2008)

Intravitreal injection of NMDA is known to be toxic to RGCs and provides a model of RGC injury that has, as its primary insult, the overactivity of NMDA receptors. As shown in Figure 12, RGC injury following injection of NMDA into the rabbit eye was quantified by counting DAPI-labeled cells in the RGC layer. RGC layer cells (RGCs \& displaced amacrine cells) were counted in a $5 \times 5$ sampling array whose superior row included the visual streak (region of highest RGC density; panelA). Intravitreal injection of $50 \mu \mathrm{L}$ saline solution containing 3.6 micromoles of NMDA resulted in the loss, at two weeks following NMDA injection, of approximately $40 \%$ of DAPI-labeled cells in the RGC layer (panel D). Co- 
injection of two different NMDA channel blockers, either MK-801 (0.12 micromoles) or memantine ( 0.36 micromoles), reduced loss to either approximately $0 \%$ or approximately $10 \%$, respectively. Co-injection of brimonidine (3.6 nanomoles) also reduced NMDAinduced RGC loss to approximately $20 \%$ and this protection was blocked by co-injection of the combination of either brimonidine + atipamezole $(24.0$ nanomoles) or brimonidine + rolipram (12-120 nanomoles). While total RGC counts are plotted in panel D, averaged counts for each of the 25 sample regions from a representative animal are plotted in panel C for each treatment group.

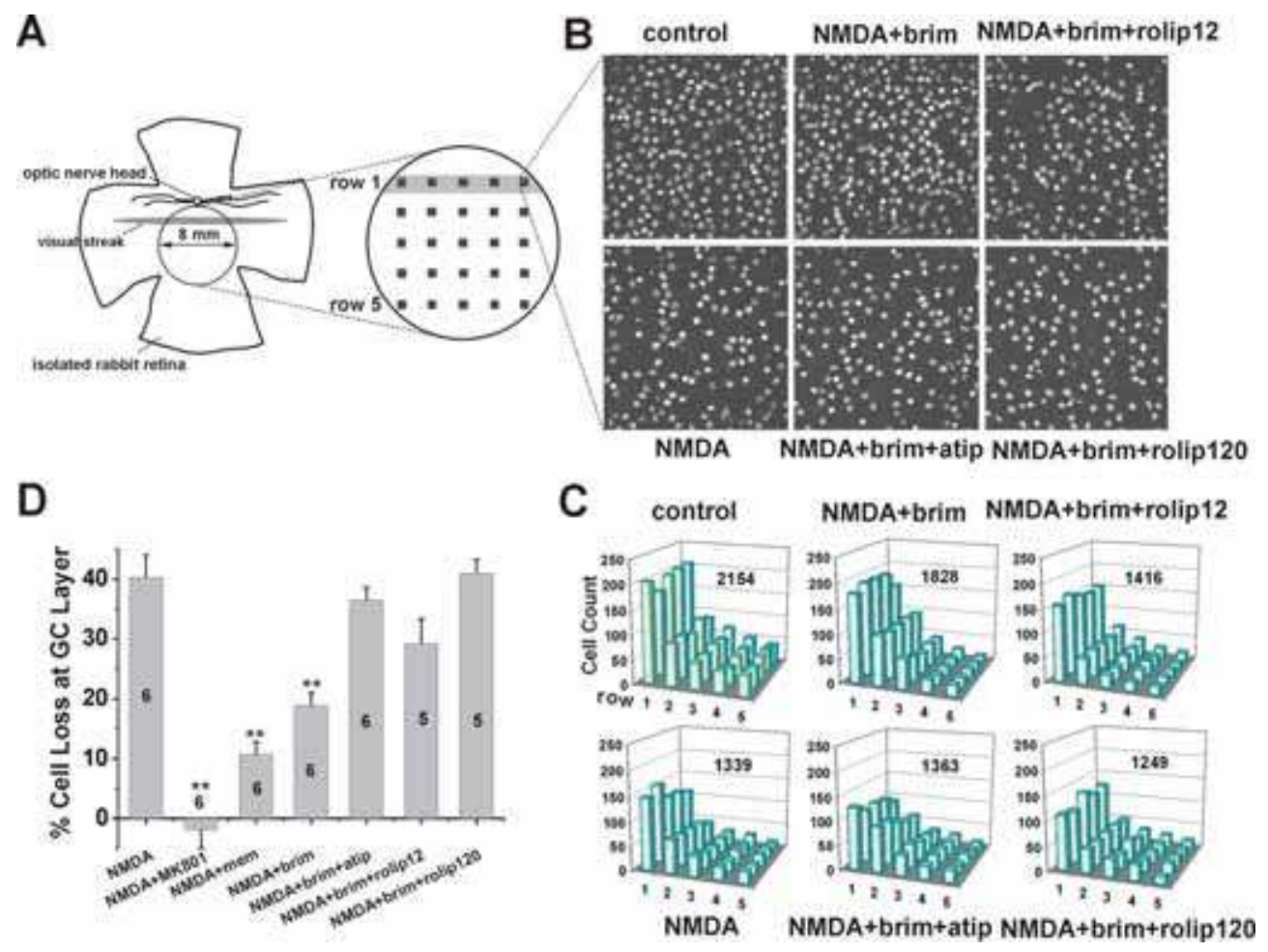

Fig. 12. Intravitreal injection of NMDA results in excitotoxic RGC loss that can be prevented or reduced with co-injection of either an NMDA channel blocker (MK-801 or memantine) or an alpha-2 receptor agonist (brimonidine). The protective effect of brimonidine is, in turn, blocked by co-injection of brimonidine in combination with a selective alpha- 2 receptor antagonist (atipamezole) or by co-injection of brimonidine in combination with a PDE4 inhibitor (rolipram). (From Dong et al., 2008)

These results show clearly that RGC injury in both the rat model for experimental glaucoma and the rabbit model for NMDA-induced excitotoxicity is driven predominantly by overactivity in NMDA-type glutamate-gated channels. Treatment with either MK- 801 or memantine reduces RGC injury by blocking directly the conductance pore of the NMDA channels, thereby reducing NMDA-induced increases in sodium and calcium ions. Brimonidine treatment reduces NMDA channel activity indirectly through a mechanism 
that includes alpha-2 receptor activation, inhibition of adenyl cyclase, and decreased levels of intracellular cAMP. Pharmacological agents that act to block brimonidine-elicited decreases in cytoplasmic cAMP also block brimonidine's action to decrease NMDA-induced currents and calcium signals in RGCs. These same agents block the protective effects of brimonidine treatment in animal models of RGC injury known to be driven predominantly by overactivity in NMDA channels.

\section{Excitotoxicity and voltage-gated sodium channels}

Visual signals are transmitted from the retina to more central visual pathways via the RGC axons. Signal transmission is coded as a temporal pattern of "spikes" or "action potentials"; each spike consisting of a regenerative depolarizing (inward) membrane current that typically travels from its generation site at the RGC soma (axon hillock) to the axon terminal in the brainstem. Axon spikes reflect the activity of voltage-gated sodium channels. At high negative resting potentials (inside negative trans-membrane voltage), these sodium channels are closed. Decreasing the membrane voltage (depolarization $=$ decreased inside negative) activates the channels and allows sodium ions to flow down their electrochemical gradient from the extracellular space into the axonal cytoplasm. This influx of sodium ions represents an inward current that spreads passively to depolarize and activate sodium channels in the immediately neighboring (resting) axonal membrane. In this manner, local inward current, generated by voltage-gated sodium channels, propagates along the axon in a regenerative fashion and transmits a wave of membrane depolarization to the axon terminal. Good temporal bandwidth for information transfer requires that these individual spike events be of very short duration. For this reason, following activation by membrane depolarization, voltage-gated sodium channels typically inactivate rapidly in a time-dependent fashion in order to move axonal membrane voltage back toward the resting level. That is, sodium channels are activated by membrane depolarization but rapidly inactivate, even in the presence of continued membrane depolarization. This property of the sodium channels is responsible for the fact that spikes are able to travel only in one direction: away from immediately active membrane and toward membrane that is "at rest". Membrane depolarization not only activates sodium channels but also inactivates them and the channels remain inactivated until membrane potential is returned toward the resting level.

Action potential generation is thus dependent upon both the sodium gradient as well as membrane voltage. The resting transmembrane sodium gradient (intracellular concentration $=$ low, extracellular concentration $=$ high) is generated by energy-dependent pumps that move sodium from the cytoplasm to the extracellular space. The same pumps contribute to both the electrical and chemical transmembrane gradient for sodium ions. The transmembrane sodium gradient provides an electrochemical energy source that is used by a wide range of membrane transporters including the sodium/calcium exchanger (SCE). The SCE uses energy available from sodium ions moving down their electrochemical gradient to transport calcium ions from the cytoplasm to the extracellular space; against both the electrical (inside negative) and chemical (calcium inside is low) gradient for calcium ions. Calcium is an important regulator of many intracellular signaling pathways and its cytoplasmic concentration is very tightly regulated at levels typically lower than a resting level of $200 \mathrm{nM}$ (Connor \& Tseng, 1988; Kirischuk et al., 1992). Even small prolonged elevations above this level can result in irreversible injury to RGCs. Any condition resulting in a loss of the electrochemical gradient for sodium ions will also be associated with, among 
other things, depolarization of the axonal membrane and increases in the cytoplasmic concentration of calcium ions.

Although the mechanisms for glaucomatous RGC injury are not known, evidence suggests that a primary insult to RGC axons at or near the optic nerve head may be a significant contributor to glaucomatous vision loss (Quigley et al., 1981; Johansson, 1986). It has been proposed that IOP can generate mechanical forces at or near the lamina cribrosa resulting in direct injury to RGC axons. These same IOP-induced stresses will compromise local vascular perfusion of the tissue resulting indirectly in ischemic insult of RGC axons (Burgoyne \& Downs, 2008). Mechanisms for ischemic injury to RGC axons have been explored using an isolated perfused rat optic nerve preparation in combination with methods for induction of experimental ischemia. For these studies, optic nerves were isolated (from eye to chiasm) from adult rats and mounted in a perfusion chamber between two suction electrodes as shown in Figure 13. Nerves were maintained at $370 \mathrm{C}$ and perfused with bicarbonate buffered ringer saturated with $95 \% \mathrm{O}_{2}$ and $5 \% \mathrm{CO}_{2}$. At one end of the nerve, a constant voltage pulse of $50 \mu \mathrm{sec}$ duration was used to drive depolarizing current through the tissue to bath ground. This current, if strong enough to reach threshold depolarization for axonal membrane sodium channels, initiates in each axon a spike that travels to the opposite end where it can be measured as a voltage. Since each axon can generate only a single spike in response to the brief stimulus pulse, the resulting composite voltage signal represents the temporal sum of all such single spikes generated in all activated axons. This composite response is therefore referred to as the compound action potential (CAP).

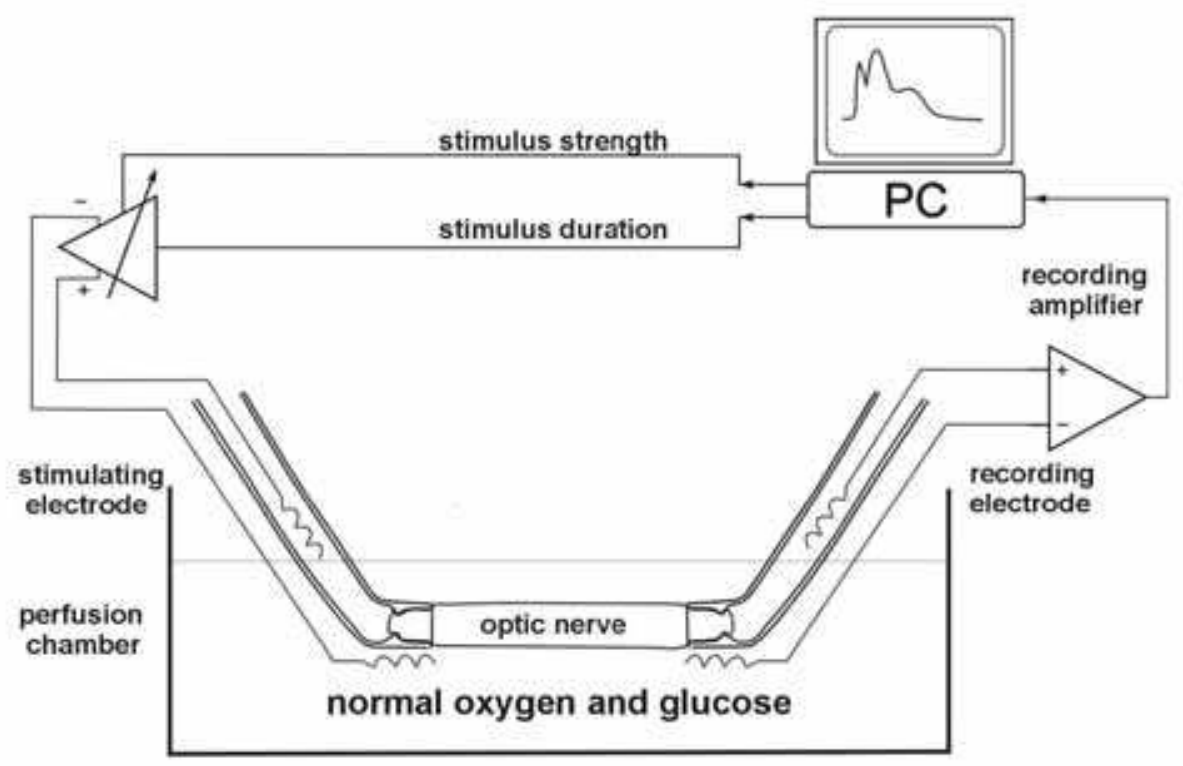

Fig. 13. Recording of the compound action potential (CAP) from the isolated rat optic nerve. (From Dong \& Hare 2005)

The two panels in Figure 14 illustrate how the CAP varies with stimulus intensity. The family of traces in panel A shows how the CAP response increases in magnitude with 
increasing stimulus voltage. That is, increasing stimulus intensity is associated with an increasing number of activated axons. The CAP waveform also clearly represents three functionally distinct axonal populations having different conduction velocities. Although, for these short conduction lengths, there is considerable temporal overlap of the three spike populations, it can be seen that the fastest spikes (large neurons, large axons) have the lowest stimulus voltage activation threshold while the slowest spikes (small RGCs, small axons) have the highest threshold. Due to the temporal overlap of spikes from the three different groups of axons, integrated CAP response area was measured instead of peak amplitude as indicated in panel B. Panel B also shows that CAP amplitude (area) saturated at a stimulus intensity of approximately 150 volts which was used for all subsequent experiments since this intensity is expected to activate all functional axons.
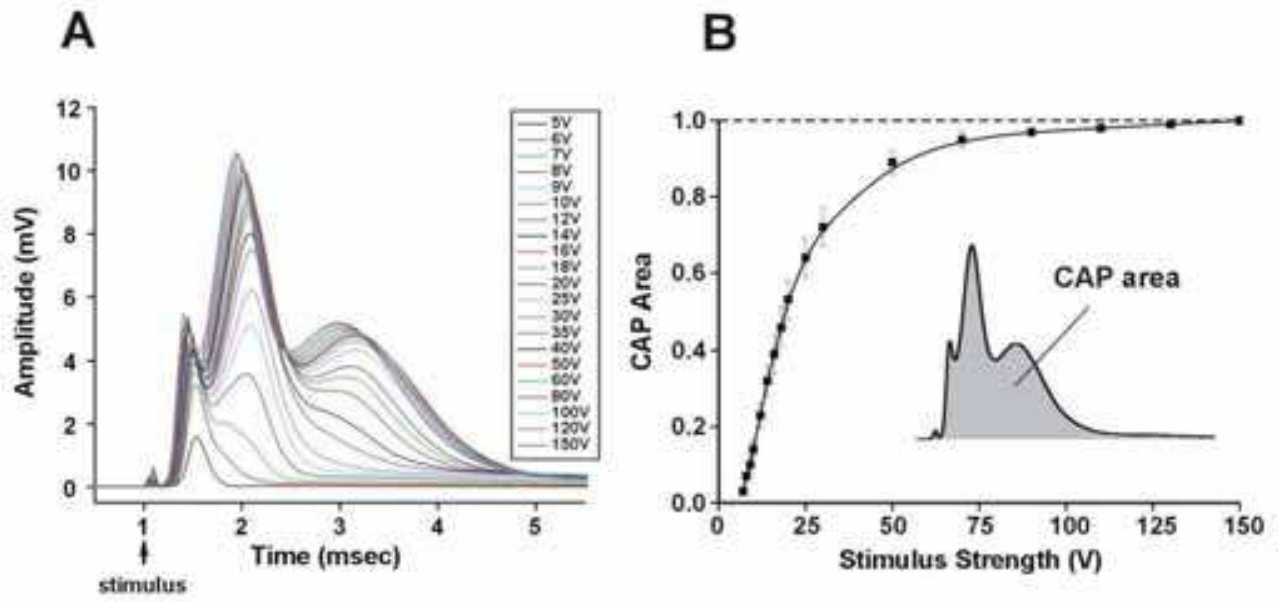

Fig. 14. CAP response as a function of stimulus intensity (voltage). Response amplitude is measured as the area of the CAP response. (From Dong \& Hare, 2005)

Experimental ischemia was induced by switching to a perfusion medium which was saturated with nitrogen instead of oxygen and from which glucose was omitted (oxygenglucose deprivation; OGD). Figure 15 shows that, following the switch to OGD, CAP amplitude declined rapidly and was almost completely blocked after 60 minutes of OGD. The switch back to control saline was associated with a partial recovery of the CAP response. This recovery was typically stable by 20 minutes following OGD washout. Responses obtained prior to OGD (1), at the end of 60 minutes OGD (2), and at 60 minutes following switch back to control saline (3), are illustrated in panel B. The inset in panel A also shows how CAP amplitude following recovery from OGD is dependent upon the duration of OGD. A standard OGD duration of 60 minutes was used for the experiments described here.

Experimental ischemia (OGD) of 60 minutes duration is associated with approximately a $70 \%$ irreversible loss of axonal function resulting from a failure of the membrane machinery responsible for spike generation and propagation. This injury results, in turn, from loss of the transmembrane sodium gradient and the subsequent elevation of intracellular calcium. According to this model, axonal energy failure leads to loss of energy-dependent sodium 
extrusion with consequent loss of the trans-membrane sodium gradient and resting membrane potential. Under these conditions, axonal sodium gradient and membrane voltage are further reduced due to influx of sodium ions through voltage-gated sodium channels. Although most membrane sodium channels are inactivated by membrane depolarization, a subset of these channels remains open and contributes to loss of the sodium gradient (Stys et al., 1993; Hammarstrom \& Gage, 2002). Since intracellular calcium is normally regulated at very low intracellular levels by the action of a calcium extrusion mechanism (sodium/calcium exchanger), the loss of the membrane sodium gradient results in elevation of intracellular calcium and activation of calcium-dependent mechanisms for axonal injury (Stys et al., 1992; Garthwaite et al., 1999).

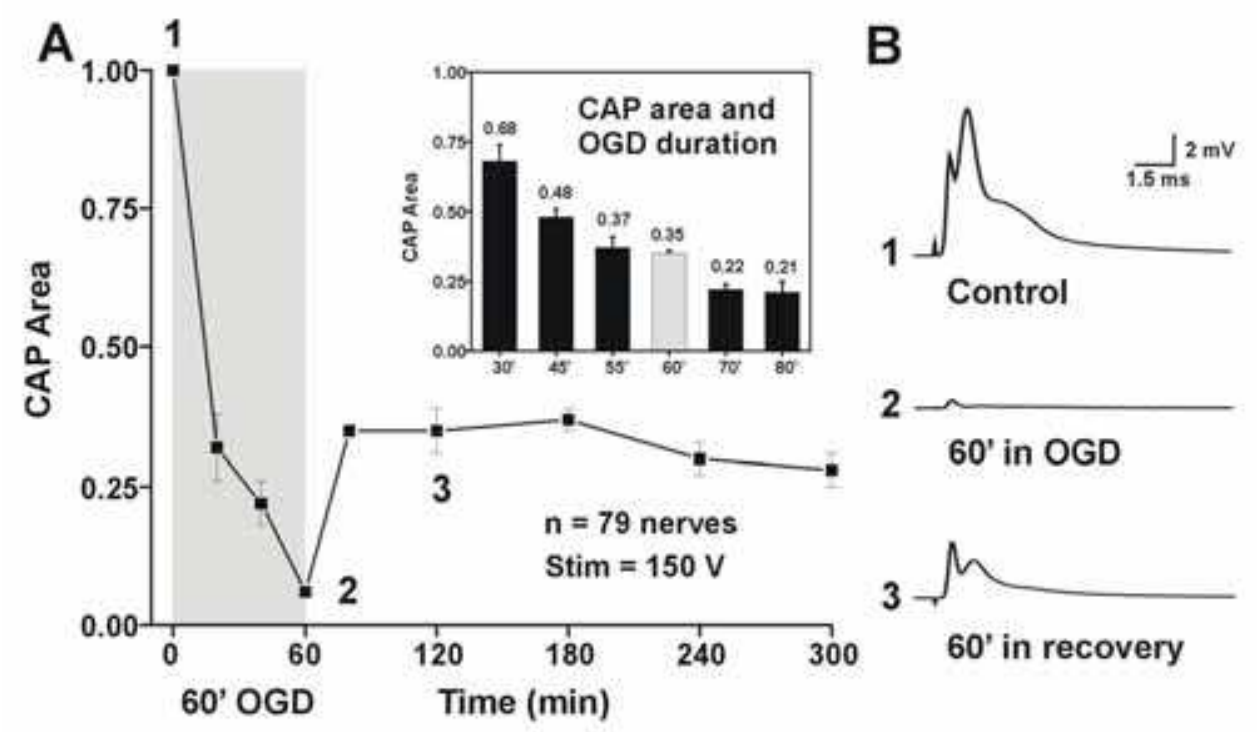

Fig. 15. OGD of 60 minutes duration is associated with irreversible loss of function in isolated rat optic nerve. (From Dong \& Hare, 2005)

The dependence of OGD-induced axonal injury on the influx of sodium ions through noninactivating voltage-gated sodium channels is illustrated by results summarized in Figure 16. Results from the control experiments of Figure 15 are re-plotted as the filled black squares in panel A. Nerves exposed to bath application of $1 \mathrm{mM}$ lidocaine (open squares), a sodium channel blocker, for 20 minutes prior to OGD as well as during the 60 minute exposure to OGD, recovered a greater level of function (CAP area) than untreated nerves. Inspection of panel A shows that pre-treatment with lidocaine is associated with complete block of the CAP by the onset of OGD. At the end of OGD, lidocaine must wash out before any protective effect can be measured. These results show clearly that OGD-induced axonal injury is mediated, at least in part, by sodium influx via voltage-gated sodium channels. This was further tested in experiments where the nerves were perfused with sodium-free medium for 20 minutes prior to and during OGD as summarized in Figure 17. The open squares plotted in panel A show that removal of sodium ions from the extracellular space reduces axonal functional loss associated with OGD; supporting the notion that injury 
depends significantly on the net flux of sodium ions from the extracellular space to the axonal cytoplasm.
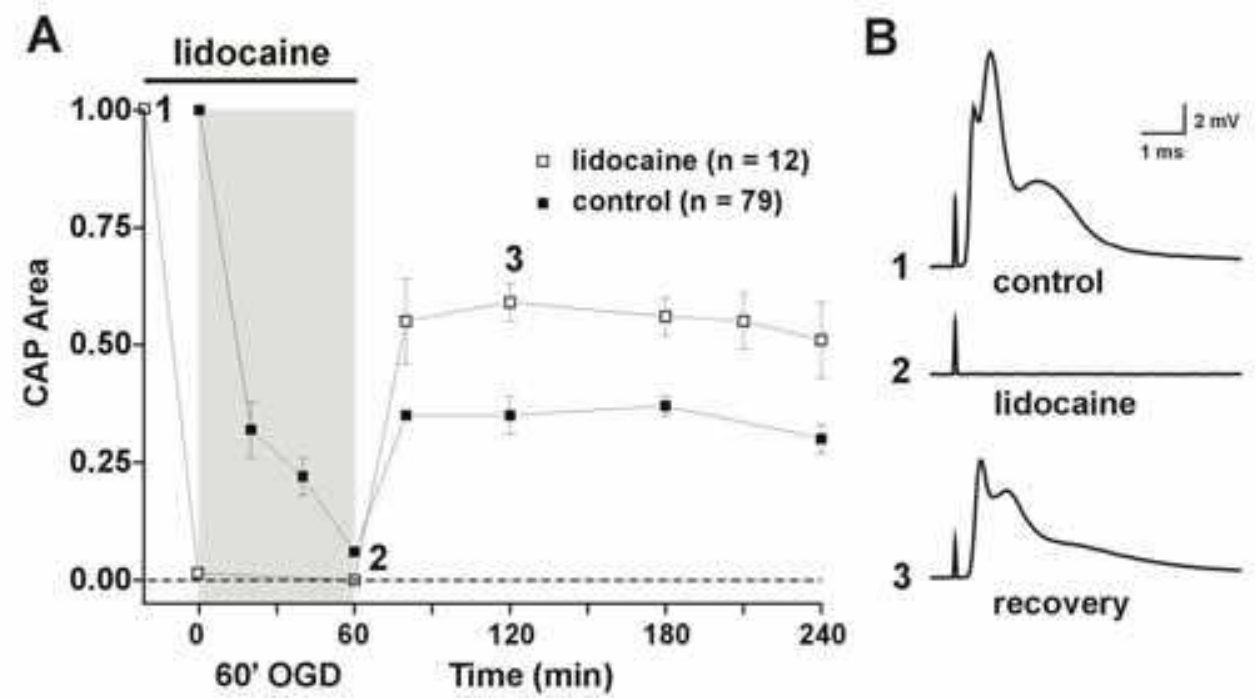

Fig. 16. Blockade of voltage-gated sodium channels with bath application of $1 \mathrm{mM}$ lidocaine (for 20 minutes preceding OGD and during OGD) reduces OGD-induced axonal injury. (From Dong \& Hare, 2005)

Removal of calcium from the perfusion medium is also associated with a reduction of OGDinduced axonal injury. Figure 18 shows that perfusion with zero-calcium medium for 20 minutes before as well as during OGD resulted in a reduction of OGD-induced axonal injury. Results from experiments using either a sodium channel blocker (lidocaine; Figure 16), zero sodium medium (Figure 17), or zero calcium medium (Figure 18) are summarized for comparison in Figure 19. Prevention of sodium overload is clearly associated with reduced OGD-induced axonal injury. The fact that perfusion with zero calcium medium, in the presence of normal extracellular sodium levels and functioning voltage-gated sodium channels, is able to reduce axonal injury suggests that increased intracellular calcium is the major driver of injury and that intracellular sodium overload leads to injury, in large part, by reducing extrusion of axonal calcium by the sodium/calcium exchanger. In fact, if the sodium gradient and membrane potential are decreased sufficiently, the exchanger can run in reverse mode to actually transport calcium into the cell and further accelerate increases in intracellular calcium.

These experiments show how intracellular sodium overload, by reducing calcium extrusion via the sodium/calcium exchanger, leads to injury of RGC axons indirectly through the elevation of intracellular calcium. Of course, sodium overload may also contribute to axonal injury resulting from loss of function in other sodium-dependent membrane transporters that, in addition to the sodium/calcium exchanger, are also necessary for axonal function/survival. For this model of acute experimental ischemic insult axonal injury is driven predominantly by failure of membrane calcium transport. Voltage gated sodium channels are also found in somato-dendritic RGC membrane where the sodium/calcium 


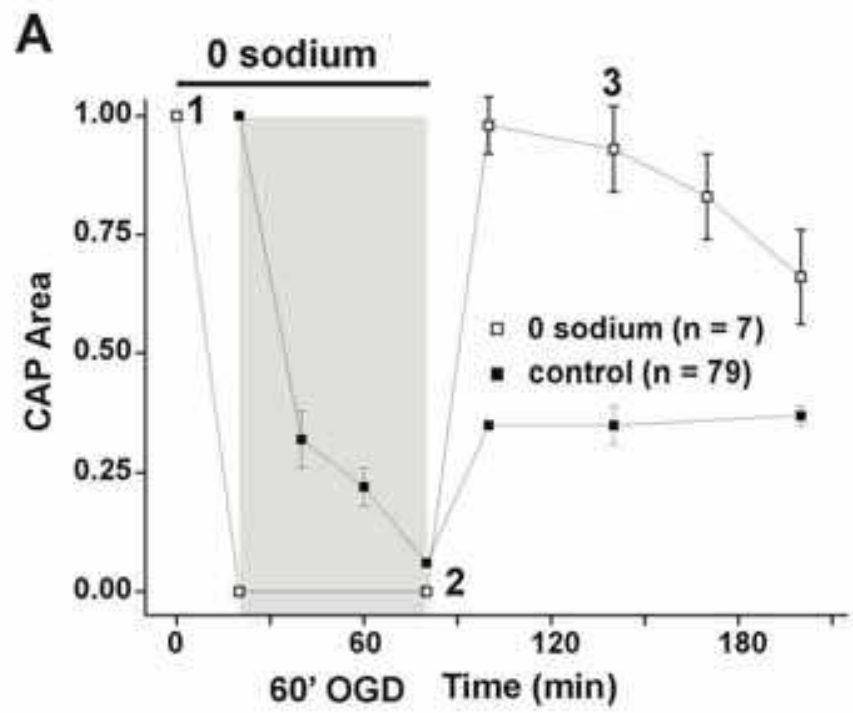

B
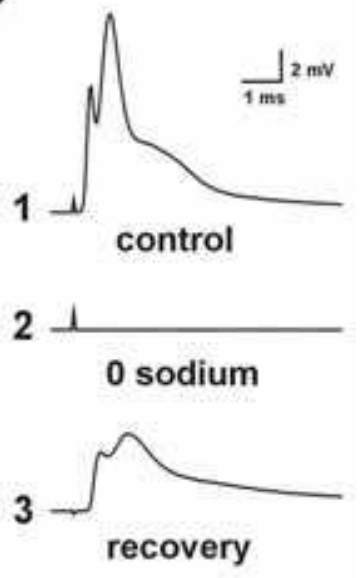

Fig. 17. Removal of sodium ions from the extracellular space (perfusion with zero sodium medium), both prior to and during OGD, reduces OGD-induced axonal injury. For zero sodium medium, sodium chloride was replaced with lithium chloride and sodium bicarbonate was replaced with choline bicarbonate. (From Dong \& Hare, 2005)
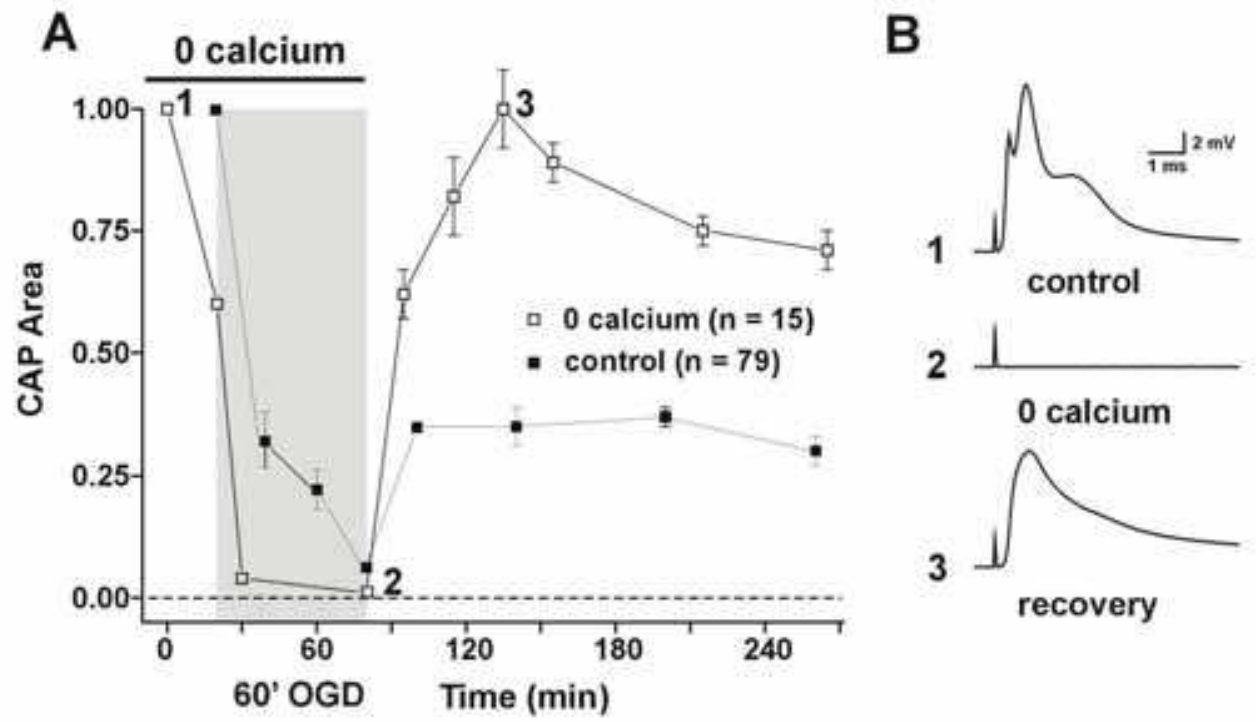

Fig. 18. Perfusion with zero-calcium medium is associated with a reduction of OGD-induced axonal injury. Calcium was omitted from the medium and replaced with 5 mM EGTA (calcium buffer). (From Dong \& Hare, 2005) 
exchanger is also an important mechanism for regulation of intracellular calcium at low levels. However, models of injury to the somato-dendritic compartment are complicated by the fact that glutamate-gated channels and voltage-gated calcium channels provide additional sources for entry of sodium and calcium ions that also contribute to RGC injury.

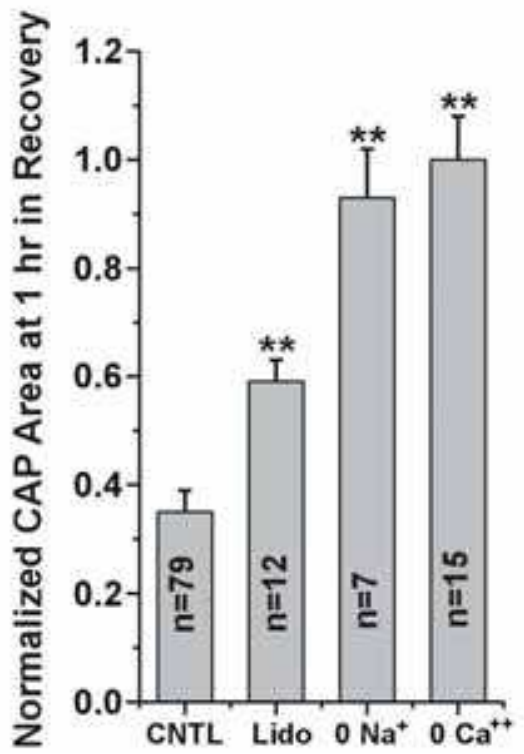

Fig. 19. Summary of results for experiments showing that blockade of sodium channels (Lido), perfusion with zero-sodium medium $\left(0 \mathrm{Na}^{+}\right)$, or perfusion with zero-calcium medium $\left(0 \mathrm{Ca}^{++}\right)$is associated with a reduction in OGD-induced axonal injury. (From Dong \& Hare, 2005)

\section{Conclusion}

Although the precise mechanism for glaucomatous injury to RGCs is not known, glutamategated ion channels and voltage-gated sodium channels are known to contribute to RGC injury resulting from a wide range of insults in both in-vitro and animal models including experimental glaucoma. Under "normal" conditions, these channels participate in the transmission of excitatory signals between neurons in the retina and central visual pathways. Under pathological conditions, overactivity of these same channels may result in elevation of intracellular sodium concentration, loss of the electrochemical transmembrane gradient for sodium ions, decreased calcium extrusion via the sodium/calcium exchanger, elevation of intracellular calcium, and activation of calcium dependent intracellular mechanisms for RGC injury.

\section{Acknowledgement}

The authors acknowledge the participation of Yuanxing Guo and Peter Agey in much of the work presented in this chapter. 


\section{References}

Aizenman, E., Frosch, MP. \& Lipton, SA. (1988) Responses mediated by excitatory amino acid receptors in solitary retinal ganglion cells, eburnal of Physiology Vol.(396):75-91.

Burgoyne, CF. \& Downs, JC. (2008) Premise and prediction-how optic nerve head biomechanics underlies the susceptibility and clinical behavior of the aged optic nerve head, eburnal of Glaucoma Vol. (17):318-328.

Chen, HS., Pellegrini, JW.,Aggarwal, SK., Lei, SZ., Warach, S., Jensen, FE. \& Lipton, SA. (1992) Open-channel block of N-methyl-D-aspartate (NMDA) responses by memantine: therapeutic advantage against NMDA receptor-mediated neurotoxicity, eburnal of Neuroscience Vol.(12):4427-4436.

Chen, HS. \& Lipton, SA. (1997) Mechanism of memantine block of NMDA-activated channels in rat retinal ganglion cells: uncompetitive antagonism, cburnal of Physiology Vol.(499):27-46.

Choi, DW. (1988) Glutamate neurotoxicity and diseases of the nervous system, Neuron Vol.(1):623-634.

Connor, JA. \& Tseng, HY. (1988) Measurement of intracellular $\mathrm{Ca}^{++}$in cerebellar purkinje neurons in culture: Resting distribution and response to glutamate, Brain Research Bulletin Vol.(21):353-361.

Craner, MJ., Lo, AC., Black, JA. \& Waxman, SG. (2003) Abnormal sodium channel distribution in optic nerve axons in a model of inflammatory demyelination, Brain Vol.(126):1552-1561.

Diamond, JS. \& Copenhagen, DR. (1993) The contribution of NMDA and non-NMDA receptors to the light-evoked input-output chacteristics of retinal ganglion cells, Neuron Vol.(11):725-738.

Donello, JE., Padillo, EU., Webster, ML., Wheeler, LA. \& Gil, DW. (2001) alpha(2)-adrenergic agonists inhibit vitreal glutamate and aspartate accumulation and preserve retinal function after transient ischemia, eburnal of Pharmacology and Experimental Therapeutics Vol.(296):216-223.

Dong, CJ. \& Hare, WA. (2005) Contribution to ischemic injury of rat optic nerves by intracellular sodium overload, Documenta Ophthalmologica Vol.(110):15-23.

Dong, CJ., Guo, Y., Agey, P., Wheeler, L. \& Hare, WA. (2008) Alpha2 adrenergic modulation of NMDA receptor function as a major mechanism of RGC protection in experimental glaucoma and retinal excitotoxicity, Investigative Ophthalmology \& Visual Science Vol.(49):4515-4522.

Garthwaite, G., Brown, G., Batchelor, AM., Goodwin, DA. \& Garthwaite, J. (1999) Mechanisms of ischemic damage to central white matter axons: A quantitative histological analysis using rat optic nerve, Neuroscience Vol.(94):1219-1230.

Gu, Z., Yamamoto, T., Kawase, C., Matsubara, M., Kawase, K., Sawada, A. \& Kitazawa, Y. (2000) Neuroprotective effect of N-methyl-D-aspartate receptor antagonists in an experimental glaucoma model in the rat, Nippon Ganka Gakkai Zasshi Vol.(104):1116.

Hammarstrom, AKM. \& Gage, PW. (2002) Hypoxia and persistent sodium current, European Biophysical burnal Vol.(31):323-330.

Hare, WA., WoldeMussie, E., Lai, RK., Ton, H., Ruiz, G., Chun, T. \& Wheeler, L. (2004a) Efficacy and safety of memantine treatment for reduction of changes associated with experimental glaucoma in monkey, I: Functional measures, Investigative Ophthalmology \& Visual Science Vol.(45):2625-2639. 
Hare, WA., WoldeMussie, E., Weinreb, R., Ton, H., Ruiz, G., Wijono, M., Feldmann, B., Zangwill, L. \& Wheeler, L. (2004b) Efficacy and safety of memantine treatment for reduction of changes associated with experimental glaucoma in monkey, II: Structural measures, Investigative Ophthalmology \& Visual Science Vol.(45):26402651.

Hare, WA. \& Wheeler, L. (2009) Experimental glutamatergic excitotoxicity in rabbit retinal ganglion cells: Block by memantine, Investigative Ophthalmology \& Visual Science Vol.(50):2940-2948.

Izumi, Y., Shimamoto, K., Benz, AM., Hammerman, SB., Olney, JW. \& Zorumski, CF. (2002) Glutamate transporters and retinal excitotoxicity, Glia Vol.(39):58-68.

Johansson, JO. (1986) Retrograde axoplasmic transport in rat optic nerve in vivo. What causes blockage at increased intraocular pressure?, Experimental Eye Research Vol.(43):653-660.

Kaneda, M. \& Kaneko, A. (1991) Voltage-gated sodium currents in isolated retinal ganglion cells of the cat: relation between the inactivation kinetics and the cell type, Neuroscience Research Vol.(11):261-275.

Kim, HS., Chang, YI., Kim, JH. \& Park, CK. (2007) Alteration of retinal intrinsic survival signal and effect of alpha2-adrenergic receptor agonist in the retina of the chronic ocular hypertension rat, Visual Neuroscience Vol.(24):127-139.

Kirischuk, S., Pronchuk, N. \& Verkhratsky, A. (1992) Measurements of intracellular calcium in sensory neurons of adult and old rats, Neuroscience Vol.(50):947-951.

Kowluru, RA., Engerman, RL., Case, GL. \& Kern, TS. (2001) Retinal glutamate in diabetes and effect of antioxidants, Neurochem. Int. Vol.(38):385-390.

Lafuente, MP., Villegas-Perez, MP, Mayor, S., Aguilera, ME., Miralles de Imperial, J. \& Vidal-Sanz, M. (2002) Neuroprotective effects of brimonidine against transient ischemia-induced retinal ganglion cell death: a dose response in vivo study, Experimental Eye Research Vol.(74):181-189.

Lagreze, WA., Knorle, R., Bach, M. \& Feuerstein, TJ. (1998) Memantine is neuroprotective in a rat model of pressure-induced ischemia, Investigative Ophthalmology \& Visual Science Vol.(39):1063-1066.

Lai, RK., Chun, T., Hasson, D., Lee, S., Mehrbod, F. \& Wheeler, L. (2002) Alpha-2 adrenoceptor agonist protects retinal function after acute retinal ischemic injury in the rat, Visual Neuroscience Vol.(19):175-185.

Lam, TT., Siew, E., Chu, R. \& Tso, MO. (1997) Ameliorative effect of MK-801 on retinal ischemia, eburnal of Ocular Pharmacology and Therapeutics Vol.(13):129-137.

Louzada-Junior, P., Dias, JJ., Santos, WF., Lachat, JJ., Bradford, HF. \& Coutinho-Netto, J. (1992) Glutamate release in experimental ischemia of the retina: an approach using microdialysis, cburnal of Neurochemistry Vol.(59):358-363.

Lucas, DR. \& Newhouse, JP. (1957) The toxic effect of sodium L-glutamate on the inner layers of the retina, A.M.A. Archives of Ophthalmology Vol.(58):193-201.

Luo, X., Heidinger, V., Picaud, S., Lambrou, G., Dreyfus, H., Sahel, J. \& Hicks, D. (2001) Selective excitotoxic degeneration of adult pig retinal ganglion cells in vitro, Investigative Ophthalmology \& Visual Science Vol.(42):1096-1106.

Ma, K., Xu, L., Zhang, H., Zhang, S., Pu, M. \& Jonas, JB. (2009) Effect of brimonidine on retinal ganglion cell survival in an optic nerve crush model, American eburnal of Ophthalmology Vol.(147):326-331. 
Massey, SC. \& Miller, RF. (1990) N-methyl-D-aspartate receptors of ganglion cells in rabbit retina, eburnal of Neurophysiology Vol.(63):16-30.

Metoki, T., Ohguro, H., Ohguro, I., Mamiya, K., Ito, T. \& Nakazawa, M. (2005) Study of effects of antiglaucoma eye drops on N-methyl-D-aspartate-induced retinal damage, elapanese eburnal of Ophthalmology Vol.(49):453-461.

Neal, MJ., Cunningham, JR., Hutson, PH. \& Hogg, J. (1994) Effects of ischemia on neurotransmitter release from the isolated retina, eburnal of Neurochemistry Vol.(62):1025-1033.

Nucci, C., Tartaglione, R., Rombola, L., Morrone, LA., Fazzi, E. \& Bagetta, G. (2005) Neurochemical evidence to implicate elevated glutamate in the mechanisms of high intraocular pressure (IOP)-induced retinal ganglion cell death in rat, Neurotoxicology Vol.(26):935-941.

Pang, IH., Wexler, EM., Nawy, S., DeSantis, L. \& Kapin, MA. (1999) Protection by eliprodil against excitotoxicity in cultured rat retinal ganglion cells, Investigative Ophthalmology \& Visual Science Vol.(40):1170-1176.

Pellegrini, JW. \& Lipton, SA. (1993) Delayed administration of memantine prevents Nmethyl-D-aspartate receptor-mediated neurotoxicity, ANN. Neurology Vol.(33):403407.

Pellegrino, RG. \& Ritchie, JM. (1984) Sodium channels in the axolemma of normal and degenerating rabbit optic nerve, Proceedings of the Royal Society (London) Vol.(222):155-160.

Quigley, HA., Addicks, EM., Green, WR. \& Maumenee, AE. (1981) Optic nerve damage in glaucoma II. The site of injury and susceptibility to damage, Archives of Ophthalmology Vol.(99):635-649.

Rothman, SM. \& Olney, JW. (1987) Excitotoxicity and the NMDA receptor, Trends In Neurosciences Vol.(10):299-302.

Schoepfer, R., Monyer, H., Sommer, B., Wisden, W., Sprengel, R., Kuner, T., Lomeli, H., Herb, A, Kohler, M. \& Burnashev, N. (1994) Molecular biology of glutamate receptors, Progress in Neurobiology Vol.(42):353-357.

Shuettauf, F., Quinto, K., Naskar, R. \& Zurakowski, D. (2002) Effects of anti-glaucoma medications on ganglion cell survival: the DBA/2J mouse model, Vision Research Vol.(42):2333-2337.

Siliprandi, R., Canella, R., Carmignoto, G., Schiavo, N., Zanellato, A., Zanoni, R. \& Vantini, G. (1992) N-methyl-D-aspartate-induced neurotoxicity in the adult rat retina, Visual Neuroscience Vol.(8):567-573.

Stys, PK., Waxman, SG. \& Ransom, BR. (1992) Ionic mechanisms of anoxic injury in mammalian CNS white matter: Role of $\mathrm{Na}^{+}$channels and $\mathrm{Na}^{+-} \mathrm{Ca}^{+2}$ exchanger, The burnal of Neuroscience Vol.(12):430-439.

Stys, PK., Sontheimer, H., Ransom, BR. \& Waxman, SG. (1993) Noninactivating tetrodotoxin-sensitive $\mathrm{Na}^{+}$conductance in rat optic nerve axons, Proceedings of the National Academy of Science Vol.(90):6976-6980.

Wolde Mussie, E., Ruiz, G., Wijono, M. \& Wheeler, L. (2001) Neuroprotection of retinal ganglion cells by brimonidine in rats with laser-induced chronic ocular hypertension, Investigative Ophthalmology \& Visual Science Vol.(42):2849-2855.

Wolde Mussie, E., Yoles, E., Schwartz, M., Ruiz, G. \& Wheeler, L. (2002) Neuroprotective effect of memantine in different retinal injury models in rats, eburnal of Glaucoma Vol.(11):474-480. 
Wollner, DA., Scheinman, R. \& Catterall, W. (1988) Sodium channel expression and assembly during development of retinal ganglion cells, Neuron Vol.(8):727-737.

Yoles, E., Wheeler, L. \& Schwartz, M. (1999) Alpha2-adrenoceptor agonists are neuroprotective in a rat model of optic nerve degeneration, Investigative Ophthalmology \& Visual Science Vol.(40):65-73.

Zeevalk, GD. \& Nicklas, WJ. (1992) Evidence that the loss of the voltage-dependent $\mathrm{Mg}^{2+}$ block at the N-methyl-D-aspartate receptor underlies receptor activation during inhibition of neuronal metabolism, eburnal of Neurochemistry Vol.(59):1211-1220. 


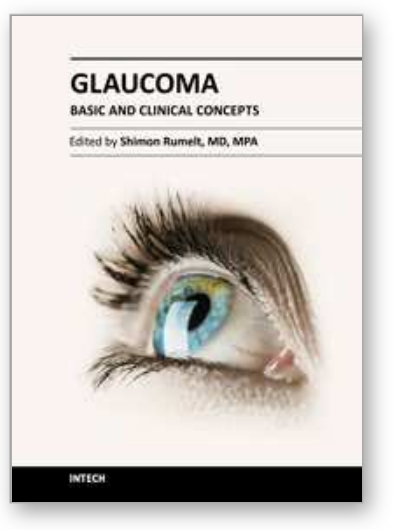

\author{
Glaucoma - Basic and Clinical Concepts \\ Edited by Dr Shimon Rumelt
}

ISBN 978-953-307-591-4

Hard cover, 590 pages

Publisher InTech

Published online 11, November, 2011

Published in print edition November, 2011

This book addresses the basic and clinical science of glaucomas, a group of diseases that affect the optic nerve and visual fields and is usually accompanied by increased intraocular pressure. The book incorporates the latest development as well as future perspectives in glaucoma, since it has expedited publication. It is aimed for specialists in glaucoma, researchers, general ophthalmologists and trainees to increase knowledge and encourage further progress in understanding and managing these complicated diseases.

\title{
How to reference
}

In order to correctly reference this scholarly work, feel free to copy and paste the following:

William A. Hare, Cun-Jian Dong, and Larry Wheeler (2011). Excitotoxic Injury to Retinal Ganglion Cells, Glaucoma - Basic and Clinical Concepts, Dr Shimon Rumelt (Ed.), ISBN: 978-953-307-591-4, InTech, Available from: http://www.intechopen.com/books/glaucoma-basic-and-clinical-concepts/excitotoxic-injury-toretinal-ganglion-cells

\section{INTECH}

open science | open minds

\section{InTech Europe}

University Campus STeP Ri

Slavka Krautzeka 83/A

51000 Rijeka, Croatia

Phone: +385 (51) 770447

Fax: +385 (51) 686166

www.intechopen.com

\section{InTech China}

Unit 405, Office Block, Hotel Equatorial Shanghai

No.65, Yan An Road (West), Shanghai, 200040, China

中国上海市延安西路65号上海国际贵都大饭店办公楼 405 单元

Phone: +86-21-62489820

Fax: $+86-21-62489821$ 
(C) 2011 The Author(s). Licensee IntechOpen. This is an open access article distributed under the terms of the Creative Commons Attribution 3.0 License, which permits unrestricted use, distribution, and reproduction in any medium, provided the original work is properly cited. 